Manuscript

January 2016

\title{
A start-up in interaction with its partners
}

\begin{abstract}
Purpose Start-ups are companies that are not yet embedded in a pre-existing network of relationships. Studies that researched how start-ups act in their relationships focused on just one type of action and assumes that start-ups are autonomous in how they choose to act. However, organisational action in relationships is both interactive and dynamic. Therefore, the researchers aim to investigate how a startup does interact with its partners over time.
\end{abstract}

Design/methodology/approach The research aim is addressed through a longitudinal case study of a start-up in the medical device business. It was analysed how this start-up and its six key partners acted and reacted during 18 interactions episodes, what triggered these actions and what the outcomes of their actions were. In addition, the researchers explored if and how the subsequent episodes were related.

Findings Firstly, the case shows that the past and the future affect current episodes. Secondly, it shows that action was triggered by both internal and external events which could expand or constrain opportunities for future interactions. Thirdly, the findings show that there was a pattern in the interaction modes used during the relationship. Fourthly, the findings show that the initial mode of interaction was often imitated by the counterparty. Finally, it is shown that there are clear links between the trigger, interaction process and outcome in an interaction episode.

Research implications The results indicate that besides the focal firm, partners should always be actively and directly involved in any research into organisational action. Moreover, action in relationships should be characterized as a dynamic process that is in a state of continual change.

Practical implications Managers of start-ups: (a) can influence the outcomes of their relationships through their actions; (b) have to react to both opportunities and conflicts in their relationships; (c) can rely on their network to solve conflicts; and (d) should closely consider their own actions and their counterparty's actions. 


\section{INTRODUCTION}

Start-ups do not emerge in a vacuum. They build on the pre-existing resource constellations, activity patterns and a web of actors in the network (Snehota, 2011). To survive in this network, start-ups have to embed themselves in the established developing, producing and using setting (Håkansson, Ford, Gadde, Snehota, \& Waluszewski, 2009). It is not sufficient for a start-up to just develop new ideas. These ideas have to be embedded in the producing and using setting to create any desirable economic effect (Håkansson \& Waluszewski, 2007). Consequently, a start-up is defined as a company that is not yet established in the pre-existing developing, producing and using setting. In these settings, the value of a start-up's resources depends on their connections to the resources of others, and the outcome of its activities is interdependent with its counterparties' activities. Therefore, start-ups are dependent on the skills, resources, actions and intentions of other organisations (Håkansson et al., 2009). This interdependence implies that organisations are interactive instead of being independently developed and implemented (Håkansson \& Ford, 2002). The Industrial Marketing and Purchasing (IMP) approach defines interaction as " $a$ constant process of action and reaction involving activities, actors and resources” (Håkansson et al., 2009, p. 197). Interaction may be unplanned and unintentional, but it is also the process through which actors try to achieve their aims. The deliberate actions of a start-up influence the extent to which its partners perceive the outcomes of the relationship as either positive or negative. Subsequently, this affects its partners' willingness to take action to either support or counteract a start-up's action and the potential outcomes (Das \& Teng, 2002; Ring \& Van de Ven, 1994). Therefore, start-ups need to know how to act so as to embed themselves in the pre-existing network and to benefit from the resources, initiatives and activities of others (Håkansson \& Ford, 2002; Lui \& Ngo, 2005).

Yet start-ups face unique challenges in interaction. Their lack of experience, reputation and resources makes it more difficult to know how to act in a relationship (Ariño, Ragozzino, \& Reuer, 2008). Nevertheless, start-ups contribute their own resources and activities to a relationship, just like any other organisation. Moreover, they are able to control, change and adapt these resources and activities. As a result, start-ups have room for taking action and making changes to reach their aims in interaction (Håkansson, Olsen, \& Bakken, 2013). They need "to act, to try to control, co-ordinate and influence, to suggest ideas and initiative, to set limits and to seek opportunities" (Harrison, Holmen, \& Pedersen, 2010, p. 948). Consequently, there is an increasing interest in how start-ups interact with the organisations in their network. Within the IMP approach scholars have researched how start-ups initiate new relationships with customers (La Rocca, Ford, \& Snehota, 2013). Moreover, it was investigated how a small company should interact in its business network (Raesfeld \& Roos, 2008). Furthermore, the patterns of start-ups' network development have been studied (Aaboen, Dubois, \& Lind, 2011, 2013). However, the greater part of the IMP research deals with firms that are well established in their networks and enjoy long-term, close relationships. In comparison, there are only a few studies on the initiation of relationships, especially by start-ups.

Outside the IMP approach, there is increasing interest in the specific actions that start-ups take in their relationships. For example, Thorgren, Wincent, and Boter (2012) demonstrated that small firms are more likely to comply with group norms than large firms. Also, Ariño et al. (2008) found that entrepreneurial firms are more likely to avoid the problem of governance misalignment than established companies. These previous studies addressed a single type of action in each paper, i.e. compliance and avoidance. Yet neither took other possible types of actions, such as defiance or manipulation, into account. This focus on just one type of action limits our understanding of how a start-up uses different types of actions over time (Tjemkes \& Furrer, 2010). Organisations take a variety of actions over time to achieve their goals. At one point in time, a start-up may support the actions of their partners to retain their goodwill. At another point in time, it needs to confront some aspects of the relationship to improve efficiency in activities and create a development path for resources (Håkansson et al., 2009). Therefore, the actions of start-ups should be analysed by studying the way in which an action occurs in relation to other actions preceding and following it (Lui \& Ngo, 2005). Secondly, a one-sided focus on organisational action restricts our insight into how the actions of start-ups interact with their partners' actions and in turn affect the counterparties involved, the relationship and the network. In a relationship, organisational action always takes place during 
interaction with the counterparty. Consequently, the freedom of an organisation to take action is limited and the outcomes of an action are not unequivocally related to the action of a single organisation (Håkansson et al., 2009). Therefore, the action of start-ups should be characterised by the unique set of interaction patterns created by the actions and reactions that go back and forth between them and their partners (Lui \& Ngo, 2005).

In conclusion, the quest for explaining start-ups' actions has been to focus on how start-ups interact with their partners, and to propose process-focused explanations in their attempt to embed themselves in a pre-existing network (Snehota, 2011). Therefore, the aim of this paper is to study how a start-up interacts with its partners over time in order to embed itself in the established developing, producing and using setting. For this purpose, a case study was conducted on a Dutch start-up. This start-up collaborates with several organisations to develop a new medical device for the treatment of diabetes. Longitudinal data was collected from both the start-up and its partners to capture the interactive and dynamic nature of organisational action. The paper establishes a theoretical framework based on relevant, current literature. In the Methodology section, a brief description is given of the research design. This is followed by a detailed description of the evolution of the start-up's key relationships. Drawing from the case description, the start-up's and its partners' actions over time are identified, analysed and compared. In the Discussion, the findings of this research are compared to the theoretical framework developed in the next section. The paper ends with a short conclusion, and the theoretical and practical implications of this paper.

\section{THEORETICAL FRAMEWORK}

\section{A series of sequential episodes represent the interaction process}

Interaction in business relationships is a process that is always in a state of ongoing change. All parties will continually make adjustments to the specific relationship as a result of their extensive interaction at the actor, resource and activity levels (Håkansson et al., 2009; Snehota, 2011). Consequently, relationships are intrinsically dynamic (Snehota, 2011). Dynamics can be considered as a series of sequential 'episodes' within a continuous interaction process. Episodes are related to each other because interaction is affected by what has taken place previously, and by the perceptions and expectations of future interaction (Ford, Gadde, Håkansson, Snehota, \& Waluszewski, 2008; Håkansson et al., 2009). A single episode can be interpreted as a specific point of interaction in time in which two or more organisations are dealing with particular matters. Each episode follows its own logic for the start-up: it involves specific partners, it deals with certain aspects of the relationship and takes place in a particular context. Most interaction episodes will be perceived as a repetitive sequence of 'normal' interactions as long as the counterparties comply with their formal and informal agreements (Håkansson et al., 2009; Lui \& Ngo, 2005). For a start-up and its partners, these interactions are part of everyday life: a normal flow of orders, payments and deliveries. In such a situation, their approach to interaction is often the unconscious result of inertia and simply continues the status quo. As a result, the process of interaction occurs routinely without deliberate effort or planning by any of the organisations involved (Ford et al., 2008; Håkansson et al., 2009).

\section{External and internal triggers that change the opportunities for future interactions}

Many events occur as a start-up and its partners interact, but these are not all perceived as important. However, events that change the nature of the possible future interaction from either of the counterparties' perspectives may disrupt the otherwise repetitive sequence of 'normal' interactions (Ford et al., 2008; Lui \& Ngo, 2005). Such events may arise from either inside or outside the interaction context (Ariño \& de la Torre, 1998; Medlin, 2004). Internally, a start-up and its partners continuously monitor the specific relationship to judge its value (Ariño \& de la Torre, 1998; Lui \& Ngo, 2005; Ring \& Van de Ven, 1994). These assessments involve considerations of potential, costs, portfolio and network position, time and the view of the relationship held by a counterparty (Ford \& Mouzas, 2008). A similar re-evaluation process takes place when external changes in environmental conditions or the strategic context alter the relationship's expected value to a counterparty. When internal assessments and external events influence the expected value of the relationship to a start-up and its partners (Ariño \& de la Torre, 1998), it will have an impact on their judgement of the activity 
links, resource ties and actor bonds. A trigger can be considered as an element of newness - internally or externally - in interaction that constrains or expands the opportunities for future interaction. Organisations have to continuously adapt to - often unexpected - internal and external elements of newness in their relationships (Ford et al., 2008). Such adaptations involve the two partners taking specific action towards each other (Lui \& Ngo, 2005; Parkhe, 1998). These actions help to restore a new repetitive sequence of 'normal' interactions (Ariño et al., 2008; Ford \& Mouzas, 2008; Medlin, 2004). In this situation, action is often in line with a clear goal or strategy followed by one or both counterparties. It may involve extensive planning, development, negotiation, bargaining or conflict (Ford et al., 2008). As the action taken during this period of change will broaden or narrow the options for future development, a start-up will frequently have to consider its actions (Ford \& Mouzas, 2008; Håkansson \& Waluszewski, 2013).

\section{Modes of interaction to consciously affect interaction}

As explained previously, strategic management researchers studying organisational action in relationships (e.g. Ariño et al., 2008; Lui \& Ngo, 2005; Thorgren et al., 2012; Tjemkes \& Furrer, 2010) assumed that organisations are autonomous in how they choose to act and how their actions result in certain outcomes for them. Moreover, these researchers presumed that organisations can and do behave purposefully to achieve these outcomes. However, the IMP approach has shown that organisational acting is never one-sided. As a result, outcomes are not unequivocally related to an organisation's behaviour. Instead, the outcomes of an actor's actions arise from the action-reaction loops of both counterparties in the relationship regardless of their intent (Håkansson et al., 2009). Although start-ups cannot determine the outcome of a relationship autonomously through their behaviour, they do seek to behave purposefully. They tend to act in a very self-conscious way, trying to force their counterparties to adapt to their intent (Aaboen et al., 2011, 2013; Håkansson et al., 2009; Harrison et al., 2010; La Rocca et al., 2013). Therefore, it is still relevant to approach start-ups in terms of their acting in relationships. Yet in this paper, the organisational actions defined by strategic management researchers are considered 'modes of interaction'. Mode of interaction refers to the way in which an organisation consciously attempts to affect interaction. This definition takes into account that organisations are not autonomous in their actions and that only via a process of interaction between two or more counterparties, actions do result in outcomes. The various modes of interaction are further explained in the next section.

\section{Interaction: the action-reaction loops between counterparties}

During an interaction episode, a number of 'action-reaction' loops are set in motion (Ariño \& de la Torre, 1998). Therefore, Lui and Ngo (2005) suggest that each relationship is characterised by a unique interaction process created by the actions and reactions that go back and forth between the partners. The interaction process is a process of change that occurs between the counterparties over time. This process and its content may be separated from the two organisations themselves. The interaction process is influenced by how both counterparties act and react as well as the process of interaction itself. As a consequence, the interaction process derives its unique character from the two involved organisations but develops in a way that is not fully controlled by either of them. Thus, what an organisation can do or accomplishes becomes the outcome of the process of interaction, action and reaction, move and countermove (Ford et al., 2008; Håkansson et al., 2009).

\section{The outcome of interaction on the actors involved, their resources and activities}

The outcome of the interaction process can be defined as the effect on the actors involved in it, the resources they exchange and the activities they perform. Interaction always affects the actors, resources and activities involved in it since it injects some novelty into the relationship. However, a single episode will affect each of those involved in it differently, and therefore will be differently interpreted by each of them (Ford et al., 2008; Håkansson et al., 2009). In general, interactions with a 'converting' character stimulate further development of activity links, resource ties and actor bonds. In contrast, actions with an 'inhibiting' character limit the progress of the relationship (Edvardsson, Holmlund, \& Strandvik, 2008; Elo \& Törnroos, 2005). Each interaction will affect subsequent interaction between the counterparties and others in multiple directions. This multidimensionality makes outcomes difficult to interpret (Ford et al., 2008; Håkansson et al., 2009). 
In summary, Figure 1 shows the process of interaction between a start-up and its partners. The arrows from the trigger to both counterparties represent that any event - whether external or internal - that changes the opportunity for further interaction may trigger action from either partner. The arrows from the start-up and its partners to the spiral represent the modes of interaction to further interaction of both counterparties. The arrows from the spiral towards the start-up and its partners represent their interpretation and assessment of what has emerged from the interaction and what have been their counterparty's intentions and modes of interaction. The spiral itself is a representation of the process of interaction. The arrow from the spiral to the outcome is intended to show that the connection from the start-up's or its partners' mode of action to the outcome is beyond their individual control. Together these represent a single episode of interaction in which two or more organisations are dealing with certain issues. In contrast, the arrows from the outcome to both counterparties show that an outcome may result in new modes of interaction by the partners, while the arrow to the trigger expresses that a new event may occur that subsequently brings about action by both partners. This emphasises that episodes are related to each other because they are affected by what has happened previously. Based on the process of interaction shown in Figure 1, five research questions were developed that will be addressed in this paper:

1. How are the interaction episodes between a start-up and its partner interlinked?

2. What triggers deliberate action by a start-up and its partner?

3. What modes of interaction do a start-up and its partner use?

4. How do the interaction modes of a start-up and its partner co-occur?

5. What is the usual outcome of the interaction process between a start-up and its partner?

\section{< Insert Figure 1 about here >}

\section{Action in an interactive process: modes of interaction}

The modes of interaction are identified based on the work of Lui and Ngo (2005) and Tjemkes and Furrer (2010). They developed typologies of actions that organisations take in their relationships. These typologies are based on research into the long-term relationships between established organisations. Yet recent studies have found that single actions of these typologies also apply to startups (Ariño et al., 2008; Thorgren et al., 2012). Therefore, it is assumed that these action typologies are also useful for studying the emerging relationship between start-ups and their counterparties. Yet in contrast to previous work on a start-up's actions in relationships, this paper aims to identify the variety of interaction modes used by a start-up. As explained previously, a start-up will never use only one type of action. Instead it will use various modes of interaction: at the same time in various relationships and at various times in the same relationship. Therefore, a focus on a single type of action would limit our understanding of the range of alternative interaction modes that are available to and are used by start-ups (Tjemkes \& Furrer, 2010). Next, the typologies of Lui and Ngo (2005) and Tjemkes and Furrer (2010) are explained, compared and integrated to identify the possible range of interaction modes that start-ups and their partners may use in their relationships.

A typology including five strategic responses to external institutional processes was developed by Oliver (1991). Lui and Ngo (2005) show that Oliver's typology can be extended to cooperative relationships by conceptualising an organisation's action as exerting external pressure on its counterparty. Specifically, they propose five types of organisational actions in a cooperative context: acquiesce, compromise, avoid, defy and manipulate. Acquiesce refers to the compliance of an organisation with the request or action of the counterparty even against its own short-term interests. Organisations do this either to strategically improve the relationship or simply out of habit. Compromise consists of the partial conformance of an organisation to the demand or action of its counterparty. The organisation negotiates to seek concessions to partially change its counterparty's demand or action. Avoid involves the lack of intention of an organisation to fulfil the counterparty's request or action. Yet the organisation typically conceals this non-compliance by reducing contact so that it can delay its response. Defy refers to an organisation's dismissal of the demand or action of its 
counterparty by rejecting and denouncing the relationship. In extreme cases, this may lead to termination of the relationship. Manipulate consists of the attempt of an organisation to influence, shape, change or redefine the demand or request of its counterparty with the aim of overpowering it (Lui \& Ngo, 2005).

Similarly, Hirschman (1970) proposed a typology in which exit, voice and loyalty represent three response strategies to decline in firms, organisations and states. Farrell (1983) extended this typology with a fourth strategy - neglect - to form the ELVN (exit-voice-loyalty-neglect) typology. Several studies have used this typology to study response strategies in a cooperative context (e.g. Geyskens \& Steenkamp, 2000; Ping, 1993, 1999). In the relationship context, the four EVLN response strategies are defined as follows. Exit indicates the willingness of an organisation to discontinue a current relationship. Relationship termination is the ultimate response to a troublesome situation (Ping, 1999). Voice refers to the attempt of an organisation to overcome an adverse situation by considering the concerns of its counterparty as well as its own. The organisation and its counterparty cooperatively discuss the issue with the intent to develop mutually satisfactory solutions. Loyalty implies an organisation's ignorance of a negative situation in the hope that it will resolve by itself (Ping, 1993). Neglect consists of an organisation allowing its relationship to decline. The organisation expends little effort in maintaining the relationship. Moreover, solutions to solve the undesirable situation are ignored (Ping, 1993, 1999; Pressey \& Qiu, 2007). Tjemkes and Furrer (2010) name the EVLN type of voice 'considerate' because it mostly suggests a positive approach involving the constructive discussion of the adverse situation. In addition, they extend the ELVN typology with three additional responses: creative voice, aggressive voice and opportunism. Creative voice refers to the attempt of an organisation and its counterparty to overcome an adverse situation by the generation of novel and potentially innovative solutions beyond the scope of their original agreement. Aggressive voice consists of the persistent effort of an organisation to solve an undesirable situation without regard for the ideas and preferences of the counterparty. The organisation coerces its counterparty into a one-side solution without trying to avoid conflict. Opportunism occurs when an organisation tries to maximize its own short-term interest at the expense of its partners. The organisation benefits from the relationship in ways that are explicitly or implicitly forbidden within the relationship.

There are clearly similarities between the typologies developed by Lui and Ngo (2005) on the one hand and Tjemkes and Furrer (2010) on the other. Firstly, compromise and considerate voice both refer to the active and constructive negotiation between an organisation and its counterparty in a relationship-preserving manner. Secondly, avoid consists of neglecting to react to an emerging issue with an organisation's counterparty. Tjemkes and Furrer (2010) argue that the issue can resolve by itself (loyalty) or the relationship will start to deteriorate (neglect). Thirdly, defy is similar to opportunistic behaviour depicted in transaction cost theory (Lui \& Ngo, 2005), and therefore is similar to opportunism as well. As defiance may lead to termination of the relationship in extreme cases, it is also closely linked with exit. Fourthly, manipulate and aggressive voice both involve the forceful effort of an organisation to change its relationship without taking the interests of its counterparty into account. However, the action acquiesce proposed by Lui and Ngo (2005) and the response strategy create described by Tjemkes and Furrer (2010) do not match any of the actions from the other typology.

From this explanation and comparison, it can be concluded that a start-up and its partners can choose from six modes of interaction: create, acquiesce, compromise, manipulate, avoid and defy. The first mode of interaction is termed 'create' and relates to the creative voice response strategy described by Tjemkes and Furrer (2010). The five other modes of interaction refer to the actions defined by Lui and Ngo (2005). Compromise and manipulate find their topological equivalent in typology of Tjemkes and Furrer (2010): considerate voice and aggressive voice respectively. Yet the labels of Lui and Ngo (2005) are used because they appear to be more action-oriented. Furthermore, it is acknowledged the latter two modes of interaction - avoid and defy - have a two-dimensional outcome. When the action of the counterparty or the adverse situation is avoided the issue dissolves naturally or the relationship declines. When the action of the counterparty or the troublesome situation is defied, then this may lead to opportunism or exit (Tjemkes \& Furrer, 2010). However, the various outcomes are not regarded as 
separate actions because the actual behaviour in both cases is similar: avoidance and defiance respectively. Table 1 summarises the definitions of the interaction modes applied in this study.

\section{$<$ Insert Table 1 about here >}

\section{METHODOLOGY}

\section{Methodological approach}

A process research approach is used to address the research questions of this paper. Process studies focus attention on how things and processes emerge, develop, grow or terminate over time. It draws on theorising that explicitly incorporates time as an element of explanation and understanding, and focusses empirically on evolving phenomena. Previous research into organisational action in relationships mainly provided timeless proposition statements, typically generated in variance theorising. The particulars of what makes action actionable -what to do, at what point in time, in what context - were not included. Yet many studies, both within and outside the IMP approach, have revealed that temporality is important and inescapable in organisational life in general and relationships in particular (Bizzi \& Langley, 2012; Halinen, Medlin, \& Törnroos, 2012; Langley, Smallman, Tsoukas, \& Van de Ven, 2013). Organisational action takes place in an ongoing process of interaction as exemplified in Figure 1. Thus, by taking time as the central element of study, this paper aims to offer an essential contribution to organisational and management knowledge that is not available from most variance-based generalisations.

\section{Subject of study}

Process research methodologies are often based on qualitative case studies. Case studies enable the researchers to capture the nuances of processes in and around organisations (Bizzi \& Langley, 2012; Langley et al., 2013). Therefore, they correspond well to a research approach that emphasises process questions. Consequently, the empirical data collection involved an in-depth case study of a start-up and its partners in the medical device business. The start-up is currently developing a new solution to improve the treatment of Type 1 diabetes patients: a closed-loop bi-hormonal artificial pancreas. However, its system is not ready to be produced, let alone be used by diabetes patients. Consequently, the company is not yet embedded in the producing and using setting. Therefore, it can still be considered a start-up. Developing all the required resources and activities in-house to embed in the pre-existing network is beyond the scope of the start-up. Therefore, it needs to collaborate with a wide range of partners to develop, produce and market the artificial pancreas. Specifically, the start-up has a key relationship with: a teaching hospital to carry out clinical trials on the artificial pancreas; a health foundation to create awareness among patients, diabetes nurses and physicians; a glucagon company to develop a new type of glucagon suitable for the artificial pancreas; a research institute to develop a new type of sensor that more accurately measures blood glucose levels; and a market leader in the diabetes device market to facilitate the marketing, sales and distribution of the artificial pancreas as soon as it is market ready. Moreover, it is involved in a European funded project with six other organisations from five different countries: a teaching hospital (NL), a technical university (NL), a medical university (AT), an established industry player (DK), a clinical research institute (DE) and a software company (TR). The project aims to advance the development of the artificial pancreas to be able to bring it to the homes of patients as quickly as possible. It would not have been possible for the start-up to develop a new treatment for diabetes without the support of its partners due to a lack of inhouse knowledge and resources.

\section{Data collection}

Longitudinal data is a key feature of process research because it is necessary to observe how processes unfold over time (Langley et al., 2013). Therefore, a retrospective analysis was conducted from the start of the project in 2004 until April 2013. Afterwards, the start-up was followed in real time until the end of December 2014. The combination of the retrospective analysis with real-time longitudinal research allows both the detection of substantial changes in relationships over long time periods and the ongoing development of relationships as they emerge (Bizzi \& Langley, 2012; Leonard-Barton, 
1990). The analysis is based on empirical data collection from three different sources: semi-structured interviews, observations and archival documents. On the one hand, this is to be able to capture the full complexity of the interaction in the relationship between the start-up and it partners (Bizzi \& Langley, 2012); on the other, to eliminate the risk that a finding is found by chance alone, which is crucial since this study is based on a single case (Doorewaard \& Verschuren, 2010; Gibbert, Ruigrok, \& Wicki, 2008). Firstly, direct passive and active participant observations were carried out during one of the researchers' residence at the start-up for on average of two days a week from April 2013 until December 2014. The prolonged involvement of the researcher in the processes studied enabled her to build interaction expertise and provided close access to events and actions (Langley et al., 2013). Moreover, it allowed the researcher to discover the discrepancies between what participants say they do and what they actually do. To reduce the researcher's hindsight bias, once every week a short evaluation report was written based on the field notes taken during that week. Secondly, archival documents, such as non-disclosure agreements, project descriptions and patents, are used to minimise interviewee hindsight bias and the limitations of memory recall (Langley et al., 2013).

Finally, fifteen semi-structured interviews were held with key individuals from the start-up and its partners at two moments in time as shown in Table 2. Although collecting data on both sides of the relationship at two moments in time is challenging, it allows the researchers to capture the interactive nature of action: in other words, the pattern of action and reaction between the start-up and its partners over time. Moreover, the various perceptions of triggers, actions, reactions and outcomes can be considered. This complements existing cross-sectional research that collects data from a single organisation per relationship (Ariño et al., 2008; Lui \& Ngo, 2005; Thorgren et al., 2012). The selection of interviewees was based on: (1) direct interaction with the other partner(s) in the relationship; and (2) the direct involvement in the development of the start-up's artificial pancreas. The first set of interviews was held in June and July 2013, while the second set followed in December 2014. Each interview lasted approximately between 30 and 100 minutes. The first set of interviews was structured around: (1) how and why the start-up and its partner initiated the relationship; (2) what the goals of the relationship were and how the start-up and its partner ensured that these goals were achieved; and (3) how resources were exchanged between the start-up and its partner. The second set of interviews focused on: (1) how the relationship between the start-up and its partner had evolved since the first interview; (2) how the goals of the relationship were revised and how the start-up and its partner ensured that these goals were achieved developed; and (3) how the resource exchange between the start-up and its partner had been modified. Then the interviewee was asked to identify: (1) important changes in the relationship; (2) how the start-up and its partners acted during these changes; (3) why they acted the way they did; and (4) how this affected their relationship. However, the interviews were flexible enough to leave room for discussion and allowed interviewees to give examples and expand on important events and situations. The interviews involved sensitive, confidential, and political topics regarding the relationship with the start-up. Consequently, it was important to maintain confidentially. Therefore, the names of organisations and interviewees were made anonymous. All interviews in this research were tape-recorded and then transcribed.

\section{< Insert Table 2 about here >}

\section{Data analysis}

To analyse the recorded interviews, diary and archival documents, ALTLAS.ti software was employed. This software provided the tools to code the findings in the data; to evaluate the importance of these findings; and visualise the complex relations between these findings. The coding was based on the theoretical framework developed in the previous section that specified important concepts $a$ priori. This helped to improve the research quality as it allowed the researchers to measure concepts more accurately. It is important to note that concepts are necessarily tentative in this type of study. The concepts could either be validated or found to be inadequate in the context of start-ups. If the validity of a concept is confirmed, then the researcher has a firmer empirical grounding for emergent theory. However, if a concept is found to be inadequate, researchers can further refine emergent theory based on the case study findings (Eisenhardt, 1989; Gibbert et al., 2008). 
The data were analysed in five consecutive phases which are summarised in Table 3 . The analysis started with drawing up a history of the start-up to clarify the context of the phenomena in question. Secondly, the analysis focused on identifying the important interaction episodes between the start-up and its partners. 'Temporal bracketing' (Langley, 1999) was used to identify comparative episodes within the stream of longitudinal data. These temporal brackets were constructed as a chain of episodes separated by identifiable internal or external triggers in the interaction process. Temporal bracketing also enabled the identification of specific actions recurring over time (Van de Ven, 1992). Therefore, the data was coded in order to identify and categorise the actions and reactions of the startup and its partners in the different episodes in the third step. The six actions adopted from Tjemkes and Furrer (2010) and Lui and Ngo (2005) as defined in Table 1 were used as the coding template. In the fourth phase the focus was on how the interaction process affected the perceived outcome of relationship as either converting or inhibiting. As explained in the previous section, interactions with a 'converting' character stimulate further development of the relationship, while actions with an 'inhibiting' character reduce activity links, resource ties and actor bonds. However, during the analysis it appeared that the partners did not always agree on the converting or inhibiting nature of the outcome of the interaction episode. In addition, the partners sometimes perceived that the interaction episode had both positive and negative outcomes. In these instances, the outcome of the interaction episode was labelled 'mixed'. Moreover, temporal bracketing permitted us to analyse how the previous episode impacts subsequent actions in the current episode (Langley et al., 2013). Finally, it was analysed how this outcome subsequently resulted in new actions or led to a new trigger: in other words, how each of the episodes was related to each other. The results of this analysis are schematically presented in Table 4, and elaborated in the next part of this paper.

\section{< Insert Table 3 about here >}

\section{RESULTS}

\section{The development of the start-up}

In 2003, an entrepreneur - a diabetic patient - consulted his diabetes nurse for his annual check-up. Over the years, he had become increasingly dissatisfied with the available treatment methods for his disease. That evening, he developed the principle of a new system: a bi-hormonal artificial pancreas. Yet the entrepreneur lacked the necessary knowledge to develop the system on his own. Therefore, he mobilised the support of two friends: a diabetes nurse and a software developer. In 2004, they were able to try out a first prototype of their system, which was the size of a small closet, on the entrepreneur. When it turned out to work as intended, the entrepreneur tested the system on a few more diabetics. The results were promising, and the friends started the development of a prototype of about the size of a microwave oven. Nevertheless, the progress stagnated between 2005 and 2008 for two main reasons. Firstly, the previous prototype was developed at the expense of the three friends. However, these funds were insufficient to finance the development of a second prototype. In 2008, this problem was resolved. The entrepreneur found an angel investor who was prepared to invest the necessary financial resources. To make this investment possible, a new company was founded in 2008: the start-up. Secondly, the start-up lacked a partner to run official clinical trials. Eventually, in 2008, the start-up came into contact with the head of a teaching hospital's diabetology group. By the end of 2011, two clinical trials were run by the teaching hospital. During this period, the start-up also came into contact with the health foundation for diabetes. This foundation appeared to have a large network of research institutes, universities, companies and non-profit organisations that were involved in diabetes-related research. For example, the health foundation brought the start-up into contact with the research institute. The start-up and the research institute had a mutual interest in developing a new glucose sensor together. Moreover, around this time the start-up began to develop a third, smaller prototype with improved functionality. The smaller artificial pancreas was about the size of approximately a laptop computer. As a consequence the start-up and the teaching hospital were able to try out the system in a home-environment. Previously, the artificial pancreas could only be tested in a hospital setting as it was too big to wear. The results of a two day trial - in a home-environment showed that the device performed as well as the regular diabetes treatment on day one and even better on day two. These promising results gave the start-up the motivation to take the project to the next 
level. Firstly, in 2012 the start-up and the teaching hospital applied for and were granted funding from the European Commission under the Seventh Framework Programme for Research and Technological Development. This funding allowed the start-up to build a fourth, even smaller, prototype of the artificial pancreas that would be suitable for introduction into the market. In addition, the grant would cover the cost of three additional clinical trials. Secondly, the development of the artificial pancreas was given a boost when the start-up won the health foundation's audience award in 2012. This award generated a lot of media attention. In this way, the project was picked up by a market leader in the diabetes device market. First the market leader was just cooperating to keep track of the start-up's invention, but after the promising results of a test with the artificial pancreas they wanted to intensify the relationship. However, the development of the start-up's artificial pancreas did not run as smoothly after 2012. The start-up and the health foundation applied for funding from the Dutch government, but this application was rejected. Additionally, the start-up had an issue with the research institute because the institute wished to change the agreements of the relationship but the start-up did not. Moreover, there was a conflict in the European project about the quality of the work that was delivered by one of the involved companies. Also, another partner decided to leave the project after one-and-a-half years. In conclusion, the start-up interacted with an increasing number of partners over the years. Consequently, there were more and more relationships that the start-up had to engage in and manage. In some instances this had a positive effect, but in others it slowed down the development of the artificial pancreas.

\section{The start-up interacting with its partners}

In this section, the interaction between the start-up and its key partners, the trigger that marked the start of the interaction episode and the outcome are explained in detail. The results are summarised in Table 4 for each partner in chronological order and will also be discussed in this way. One important aspect of this table is that there are 'white spots'. These white spots occur when either the start-up or the partner was not actively (re)acting during the interaction episode. In these episodes, one of the partners came with a request, proposal or demand to which the other party reacted, but there was no response from the initiator to its counterparty's reaction.

\section{$<$ Insert Table 4 about here >}

\section{Teaching hospital}

In 2006, the start-up started searching for a partner to run official clinical trials. These trials were necessary to advance the development of the artificial pancreas. Moreover, they were essential to gain the legitimacy in the current financial, healthcare and technical network to attract additional resources from other organisations, such as funding from investors or support from diabetes patient foundations. In 2008, the start-up came into contact with a physician who had read an article about the start-up's artificial pancreas. Although he was enthusiastic about the device, he did not have the necessary skills and facilities to conduct clinical trials. Therefore, he referred the start-up to the head of the diabetology group of a teaching hospital see Table 4, Episode 1 (hereafter there is only referred to the episode number). After some initial meetings to get to know each other, the start-up proposed that the teaching hospital would run clinical trials in exchange for shares in the start-up. The teaching hospital agreed to the type of arrangement, but wanted to cooperatively negotiate about the exact number of shares in exchange for a certain amount of work. They wished to work together because there was a clear dependency between them. As the head of the group explains, "we [the teaching hospital] do not have technical engineers that can develop diabetes technology in-house. However, we [the teaching hospital] have access to patients and clinical expertise." The outcome of the negotiation was that the teaching hospital would run three clinical trials in exchange for ten percent of the shares in the startup.

In 2011, two clinical trials were run by the teaching hospital, and these showed promising results. As described in Episode 2, the teaching hospital came across a relevant grant for funding under the Seventh Framework Programme for Research and Technological Development (FP7) from the European Commission (EC) at around the same time. Therefore, it asked the start-up if it might be interested in submitting a joint grant proposal. The start-up was very eager to agree to this suggestion 
because this grant had the potential to provide it with the necessary funds to further develop the artificial pancreas. In addition, being granted funding by the European Union would signal to the current network that the start-up was a capable partner. As the guidelines of the European Commission prescribed more than two partners, they started to search for other partners who might be interested in joining the project.

\section{European project}

At the end of 2011, the teaching hospital and the start-up found five other organisations prepared to join the project (Episode 3): a medical university (AT), an established industry player (DK), a clinical research institute (DE), a software firm (TR), and a technical university (NL). The first three were existing partners of the hospital, while the latter two were introduced by the start-up. Together the partners wrote a grant proposal that both suited their own interests and the requirements of the European Commission. It appeared to be straightforward to compromise over the agreements among them because most partners already had experience in working together. In this process, the start-up mainly agreed with the suggestions of the teaching hospital. As the entrepreneur explained: "for us [the start-up] it was the first time that we had written such a proposal. Then you just follow their [the teaching hospital's ] advice." The result was a proposal that was granted more than two million Euros of funding from the European Commission in August 2012.

As shown in Episode 4, a conflict arose between the start-up and the software company in the European project in 2014. The start-up believed that the software company was working neither effectively nor efficiently. Therefore, it wanted to do the task itself, and requested a budget shift. The software company denied this accusation, and therefore did not agree with the transfer of the budget. In response, the start-up tried to force the software company to comply with its request. This led to the conflict spiralling out of control. As a result, the software company filed a complaint to the project leader. The project leader talked extensively with the partners to explain to them that it is not in the project's interest for the issue to escalate to the point at which either the start-up or the software company leave the project (Episode 5). Eventually, they agreed to stick to their initial agreements. Although the worst part of the conflict was solved, the partners avoided further communication as much as possible. This hindered the development of the portal which the software company was building to monitor the performance of the artificial pancreas during clinical trials. Due to the lack of communication, the portal did not satisfy the requirements of the start-up.

Also in 2014, the established industry player decided to leave the project (Episode 6). The industry player was responsible for development of a stable, liquid glucagon formula. When it shut down its project to develop a stable, liquid glucagon formula, there was no motivation for the industry player to remain in the European project any longer. Most partners of the project were content with its leaving because its budget was relatively small and they did not see any opportunity to exchange more knowledge and resources. In contrast, for the start-up it resulted in the considerable challenge to find a new partner. The availability of stable, liquid glucagon was crucial for the success of the artificial pancreas. At that moment, glucagon was only stable for 24 hours and then has to be thrown away. In contrast, the start-up needed glucagon that could be used for longer. If patients had to throw away the unused glucagon every day, the costs for treatment with the artificial pancreas would become unacceptable. However, as a report from the start-up stated "for the development of the glucagon we [the start-up] depend on external partners, which makes it difficult to control... It [the industry player] is a very trusted partner. The company will deliver the glucagon in the near future, but takes its time to develop the best possible solution. Therefore, we need an alternative for when glucagon development is delayed." Thus, the start-up was already looking for alternative companies that were developing glucagon. However, the need to create an alternative partner became suddenly more urgent.

\section{Glucagon company}

After the established industry player left the European project, the start-up had to find a new partner to develop stable, liquid glucagon for its artificial pancreas; see Episode 7. Through an American health foundation, the start-up came into contact with an American company dedicated to the development of 
stable, liquid glucagon. In comparison to alterative glucagon providers, the angel investor stated "the others were not far enough [in their development]. It [the US glucagon company] was the most concrete...”. Therefore, the start-up proposed to use its glucagon in one of the next clinical trials with the artificial pancreas. The glucagon company accepted this offer because it was an effective and efficient way to test its glucagon.

Yet there was one problem; neither partner was willing to pay for the production costs of the glucagon to be used in the trial (Episode 8). Nevertheless, they were able to create a solution by using their network to find interconnections between their partners. The start-up knew an American investment company which had good relations with the American glucagon company. The start-up had also contact with this company that, although it was interested in the start-up's artificial pancreas, was not willing to invest because it was foreign initiative. Therefore, the start-up thought it might be interested in providing the funds necessary to produce the glucagon for the trial. The investment company is still reviewing if it would invest its financial resources in the glucagon provider. If the investor agrees to fund the joint project, then these funds would be employed to produce the glucagon.

\section{Health foundation}

As described in Episode 9, the entrepreneur of the start-up and the head of research the Dutch diabetes health foundation met at a donor meeting in 2009. The start-up requested funding for the development of its artificial pancreas as the health foundation is the largest financer of diabetes related research in the Netherlands. The angel investor in the start-up expected "that we [the start-up] would receive funding from it [the health foundation], but that failed". The proposal was denied by the foundation because the members of its internal audit committee did not give their approval. This approval was necessary to legitimise the funding of the start-up's project both to its auditors and to its benefactors. However, the health foundation could do more than only providing financial support. It could "also help by getting them [the start-up] in touch with other parties and researchers... We [the health foundation] can often help people in other ways to find solutions for diabetes.” Thus, the health foundation was unable to support the start-up financially, but it provided the start-up with access to its network.

In 2013, the health foundation found a way to go around the foundation's audit committee. They proposed, in collaboration with the teaching hospital and technical university, to apply for funding from the Dutch government (Episode 10). After negotiating the terms of this initiative, the partners agreed to pursue this initiative. For the start-up this was the best chance to obtain (albeit indirectly) funding from the health foundation. Furthermore, the health foundation would be able to legitimise its funding for the project to its accountants and the wider public. The proposal would be reviewed by a committee of experts composed by the government. However, the funding was not granted as a result of what the Dutch government regarded as a lack of evidence on the effectiveness of the artificial pancreas.

Before the funding application, the research foundation started a fund-raising campaign to obtain sufficient funds to finance the project. Therefore, the start-up again requested direct funding from the health foundation when the application to the Dutch government was rejected (Episode 11). For the same reasons as mentioned previously, the foundation declined. This did not benefit the relationship between the partners. They were frustrated about the fact that both parties were willing to collaborate but not able to so because of internal regulations imposed on the health foundation. Nevertheless, the start-up exerted pressure on the foundation using as leverage the funds that had already been raised to finance the rejected project (Episode 12). As a consequence of what it regarded as manipulative action, the foundation reduced its contact with the start-up. The head of research of the health foundation stated "when it turned out that it [the project application] was not successful, it [the relationship with the start-up] retreated into the background. And I no longer followed the developments closely."

\section{Research institute}

In 2012, the health foundation organized a meeting for research institutes and industry to discuss the development of new glucose sensors (Episode 14). One research institute had some initial ideas about 
a new sensor that would not only be more accurate, but also cheaper. However, it lacked an opportunity for practical application in the market. On the other hand, the start-up did not have the required knowledge to develop the sensor it needed. As a consequence of this mutual dependence, they started a four year co-financing project "in which you have steps from 10, 25, 50, and 100 percent that you [the start-up] have to fund yourself. The steps develop from scientific research to market authorization resulting in the exclusive rights." It was 'take it or leave it' for the start-up since there were no exceptions to these terms possible. The contribution from the research institute is funded from taxes, and the European legislation regarding state aid prohibits any deviations from the percentage ratios. The start-up complied with these terms because it appeared that existing sensors, which were used in the previous trials, were not sufficiently accurate.

As shown in Episode 15, an issue between the start-up and the research institute arose in 2013. After starting the relationship with the start-up, the research institute embarked on a multi-partner research program with similar goals. As the research institute perceived this project to be more efficient and less uncertain, the research institute requested the start-up to end the co-financing project, and to join the multi-partner research program. However, the terms of the research program were quite different from those of the co-financing project. The multi-partner program would enable the start-up to divide the costs of the project among several project members, but all members would be entitled to use the patent without paying a licence fee. Yet the start-up wanted the exclusive rights to the patent that would have been the result of the co-financing project first. However, the research institute did not agree to this request because the existence of a better alternative substantially reduced their dependence on the start-up. Nevertheless, the research institute was legally obliged to comply with the current contract for as long as the start-up does not agree to suspend it. The re-negotiations took about a one-and-a-half years, and in that time the progress of the joint project slowed down substantially. As the angel investor explained: "it [the research institute] has just been obstructing us [the start-up] to exert pressure to join the multi-partner program. We said we will not do that... It used all the tools to obstruct us." Although the delay did not threaten the development of the fourth prototype, the renegotiations cost the start-up precious resources.

By the end of 2014, the health foundation proposed a solution to the issue between the start-up and research institute (Episode 13 and 16). At the same time, this would solve the struggle between the start-up and the health foundation. The multi-partner program of the research institute needed knowledge that exclusively belonged to the start-up. Thus, the multi-partner program was not able to succeed without its involvement. The health foundation was one of the partners in the multi-partner program, and it wanted the multi-partner program to succeed. Therefore, it proposed to finance part of the start-up's co-financing project with the research institute up to the point to which they could apply for a patent. The condition of this funding was that the start-up would join the multi-partner research program after the patent application. This solution appeared to be a potential win-win-win situation for all three partners. The solution would enable improvement first in the 'co-financing project' and later also in the multi-partner program. In the words of the entrepreneur: "for everyone it is an opportunity to start over with new courage."

\section{Market leader}

In 2012, the start-up won the audience award of the health foundation (Episode 17). This award generated a lot of media attention. In this way, the project was picked up by a market leader in the diabetes device market. After negotiating the agreements, the start-up and the market leader signed several contracts, such as a Non-Disclosure Agreement and Right-of-First-Refusal. They agreed that aim of the relationship at this stage was mainly to explore the possibilities for more intensive collaboration. The start-up actually wanted more from the start, such as an investment or joint development program. However, the market leader did not fully agree because the risk that the artificial pancreas would fail was still perceived to be unacceptably high. Yet both partners believed that their mutual dependency could be a good basis for further more intensive collaboration. During such collaboration, the start-up could benefit from the production, sales and distribution facilities of market leader, and the market leader could profit from the innovation capabilities of the start-up. 
However, to achieve this aim the partners, especially the market leader, needed to build up a certain level of trust before they would agree to a more intensive collaboration.

During the first two years of the collaboration, the market leader's confidence in the start-up's capabilities grew. As the market leader explains: "this is clearly a step; we [the market leader] completed the exploring. We concluded that we wanted to continue with it [the relationship with the start-up].” Therefore, the market leader proposed intensifying the collaboration. Its proposal was to use its new sensor in one of the next clinical trials with the artificial pancreas (Episode 18). The startup agreed to this proposal because the market leader's sensor was the most efficient. As a result, the new sensor from the market leader would be used in one of the trials of the start-up; in this way the market leader can inexpensively test its sensor while the start-up can use the best sensor available.

\section{ANALYSIS}

The findings described in the previous section show that the start-up and its partners interacted in a way that was predicted by the research framework described in Figure 1. Therefore, the findings of the 18 interaction episodes presented previously are summarised, analysed and compared in light of the research framework in this section.

\section{A series of sequential episodes represent the interaction process}

Table 4 shows that after the five episodes with a converting outcome (there are six converting episodes, but only five were followed by a new episode), the start-up and its partners choose acquiescence, defy and manipulate as modes of interaction in the subsequent episode. Although the outcome of the previous episode was converting, they defied and manipulated when a conflict arose between the partners. Yet if the partners saw an opportunity to strengthen the relationship, they acquiesced. In spite of the successful grant for the European project, the relationship between the startup and the software company lead to a conflict. The start-up believed that the software company had worked neither efficiently nor effectively and did not expect it to do so in the future. Therefore, the start-up did manipulate the software company. In addition, Table 4 shows that in the five episodes that followed after an episode with an inhibiting outcome, the start-up and its partners choose to create, avoid, defy and manipulate. Although the outcome of the previous episode was inhibiting, they were willing to create a solution if the opportunity arose to advance the relationships in a positive direction again. However, if the partners expected that the conflict would spin out of control or the situation would not improve, they avoided, defied and manipulated. For example, when the start-up and the health foundation applied for funding this was not granted. As a result, the start-up requested direct funding from the health foundation, but this request was rejected. The frustration of the start-up caused by this rejection triggered the manipulation of the health foundation by the start-up. In turn, this resulted in the avoidance of the start-up by the foundation. Thus, the case analysis shows that the use of a particular mode of interaction in a current episode is influenced by the outcomes of previous episodes. However, the nature of the trigger also influences, even more strongly, the decision to use a particular mode of interaction.

\section{External and internal triggers that change the opportunities for future interactions}

Table 4 shows that in four out of the six relationships, the first interaction episode starts with an external trigger. In one instance, the start-up's partner initiated the first contact after publicity for the start-up in the media. In another relationship, the potential partner came into contact with the start-up at a a private meeting. In the other two instances, a third party influenced the relationship between the start-up and a specific partner. In the relationship with the teaching hospital, the start-up was referred to the head of the diabetology group by another physician, and in the relationship with the glucagon company the start-up was prompted to search for a new partner because the industry player left the European project. Thus, in the first interaction episode between the start-up and a specific partner an external trigger often marked the beginning of the relationship. Additionally, Table 4 shows that after the first episode of each relationship, interaction was triggered seven times by an external event and five times by an internal event. Internally, the start-up regularly assessed the resource ties and activity links with its partners. For example, the start-up perceived that the software company was not delivering the required quality at the required time. Externally, alterations in the strategic context of 
the start-up's partners triggered organisational actions; for example when the industry player decided to leave the European project since it had shut down its own glucagon development project. In conclusion, the results show that after the initial episode both internal and external events triggered action by the start-up and its partners.

Moreover, when the nature of the triggers in Table 4 is analysed it appears that in 12 instances the start-up and its partners agreed that the trigger expanded the opportunities for future interaction, while in four episodes they agreed that it constrained those opportunities. In the remaining two instances: (1) they did have different opinions on whether the trigger expanded or constrained the opportunities for future collaboration; or (2) the trigger expanded and constrained the opportunities for future interaction at the same time. For example, the research institute felt that the multi-partner program was an opportunity to further develop the relationship with the start-up, while the start-up thought otherwise. Furthermore, the exit of the industry player from the European project reduced the possibility of collaborating with that player, but opened up opportunities to work together with another partner. Therefore, the findings indicate that the actions of the start-up and its partners are triggered by events that both constrain and expand opportunities for future interaction, although there can be varying perspectives on the nature of the trigger. In addition, all the relationships started with opportunities for collaboration, while in four relationships in a later stage events occurred that inhibited further collaboration. Therefore, it can be argued that in the early stages there are always opportunities to collaborate, while in later stages partners are more focused on resolving conflicts as the internal and external conditions of the relationship change.

\section{Modes of interaction to consciously affect interaction}

Table 4 shows that both the start-up and its partners used a variety of interaction modes; they acquiesced, compromised, created, avoided, defied and manipulated. Although the numbers are small, the number of times that the start-up and its partners interact in a particular way can be compared. It appears that the start-up and its partners were almost equally likely to compromise, create, avoid, defy and manipulate. For example, the start-up avoided its partner once, while its partners used this mode of interaction two times. In addition, they both used a creation mode of interaction four times. Table 4 indicates that a key aspect of the interaction mode 'create' is the involvement of third parties. In all instances, the start-up and its partners were able to find novel, useful solutions to particular issues by involving a third party into the relationship. If the start-up and its partners would not have had these connections, it would have been very hard to overcome their issues. Moreover, the start-up compromised three times and its partners four times. The start-up negotiated with the teaching hospital, the health foundation and the market leader the terms of their collaboration cooperatively. Only the start-up acquiesced twice as often as its partners in the interaction episodes. For instance, the start-up acquiesced when the teaching hospital proposed to submit a grant proposal to gain funding from the European Commission and when the market leader asked if the start-up was interested in using its new sensor in the clinical trials with the artificial pancreas. To sum up, the start-up and its partners both used all modes of interaction and, with the exception of acquiescence, also to roughly the same extent.

\section{Interaction: the action-reaction loops between counterparties}

Table 4 shows that in seven episodes, the start-up and one of its partners used exactly the same mode of interaction: create-create (three times), compromise-compromise (three times) and avoid-avoid (once). In the remaining 11 episodes, the modes of interaction appeared to have the same nature in the sense that: (1) the partners both followed or at least take the interests of the counterparty into account; or (2) they only acted in accordance with their own interests. For example, the research institute attempted to force the start-up to join the multi-partner project while the start-up challenged this coercion without taking each other's interests into account. Furthermore, the partners compromised over the agreements in the proposal for the grant from the European Commission, whereas the start-up just complied with their propositions. Thus, there is a clear co-occurrence of interaction modes of the start-up and its partners within a single episode; either the interaction mode was exactly the same or had the same nature. In addition, Table 4 shows that at the beginning in three out of the six relationships the modes of interaction were acquiescing or compromising followed by defiance, 
avoidance or manipulation in later stages and subsequently creation. For example, the research institute and the start-up initiated the relationship because the institute had the knowledge to develop a new, better sensor while the start-up had the ability to commercialise it. Yet when the research institute started the multi-partner program a conflict arose about the transfer of the start-up to that program leading to defiance and manipulation. Nevertheless, they are now creating a solution to this problem by involving the health foundation. In conclusion, there appears to be a pattern in the development of the start-up's and its partners' interaction modes during the relationship.

\section{The outcome of interaction on the actors involved, their resources and activities}

It can be concluded from Table 4 that in the 12 episodes perceived to expand the opportunities for future interaction seven times the mode of interaction was acquiescence or compromise and had a (potentially) converting outcome. For example, the use of the market leader's sensors in one of the next clinical trials of the start-up can be beneficial to both. In turn, this motivated the start-up to acquiesce to the request of the market leader. Furthermore, there were three episodes with an inhibiting effect after the start-up and its partners acted by compromising, defying and ignoring in response to an opportunity. In these instances, either one of the partners was unable to take the preferred action or the interaction process was influenced by factors outside the control of both partners. The health foundation was unable to act in conformity because it was restricted by its audit committee from funding the development of the artificial pancreas. Also, the grant proposal of the start-up and the health foundation was declined by the national government. Moreover, in the remainder two episodes, the partners acted by ignorance and creation and the subsequent the outcome was mixed. Additionally, in the four episodes perceived to constrain the opportunities for further collaboration, the interaction outcome was twofold: (a) creative actions did solve the issue and had a (potentially) converting effect; and (b) defying and manipulation caused the issue to escalate and had an inhibiting effect. The same applies when the start-up and its partner did not agree whether the event was positive or negative in nature. Therefore, there appears to be a close interlinkage between trigger, mode of interaction, interaction and outcome.

\section{DISCUSSION}

The aim of this paper was to study how a start-up interacts with its partners over time in order to embed itself in the established developing, producing and using setting. The investigated start-up is clearly embedded in the developing setting. It built several relationships with the partners in the existing diabetes device development network, such as the teaching hospital and the partners of the European project. The start-up's relationships are all research and development oriented. Only following the initiation of the relationship with the market leader could the start-up take its first steps to become embedded in the producing and using settings. However, it still has a long way to go before it can actually produce the artificial pancreas and introduce it successfully into the market. To be able to become embedded in the developing setting and take the first steps into the producing and using settings, the start-up needed to interact with its partners. Without this interaction the start-up would not have been able to initiate, maintain and end its relationships in the pre-existing network.

The Results and Analysis sections show that the evolution of the interaction between the start-up and its partners over time can be characterised as a sequence of interaction episodes. These episodes are interlinked because the outcome of a previous episode affects the interaction in the subsequent episode. Moreover, Table 4 demonstrated that within each episode the start-up and a specific partner use a certain type of interaction mode - acquiesce, compromise, create, avoid, defy or manipulate - to respond to an internal or external trigger. In turn, an interaction process is set in motion in which action and reaction go back and forth between the partners. This interaction process results in a converting, inhibiting or mixed outcome for the start-up and its partners as well as for their activities and resources. To discuss each of these aspects in-depth, in this section the research questions raised in the Theoretical Framework section are addressed.

\section{A series of sequential episodes represent the interaction process}

The first research question was formulated as: How are the interaction episodes between a start-up and its partner interlinked? The analysis shows that when the previous interaction episode had a converting 
outcome, the start-up and its partners were more likely to acquiesce and compromise during the next episode. Only when a conflict between them occurred, a positive outcome of the previous interaction episode led to defiance and avoidance in the next episode. When the previous interaction episode had an inhibiting outcome, the start-up and its partners defy, avoid and manipulate in the current one. Only when an opportunity arose that allowed the partners to create a solution, the start-up and its partners acted creatively. Thus, it can be concluded from the analysis that previous episodes affect subsequent episodes. This confirms that the suggestion of Medlin (2004) and others that organisations memorize and interpret previous interaction episodes to decide on how to act in a subsequent episode. In addition, the results showed that the start-up and its partners were influenced by future expectations about the relationships. If the trigger that initiated action from either partner provided an opportunity to advance the collaboration, the future expectations of the outcome of the relationship were positive. In turn, the partners were more likely to acquiesce, compromise and create. However, if the trigger that initiated action inhibited the opportunity to maintain or develop the collaboration, the partners had negative expectations of the outcome of the relationship. As a result, the partners would be more inclined to avoid, defy and manipulate. Indeed the IMP approach argues that not only history impacts on the interaction in a current episode, but also the expectations about future interaction. A particular action can either positively or negatively impact the economic, technical and social outcomes of the interaction episode. If an organisation expects that the potential outcome will be less efficient than it could be, thereby harming innovation and reducing legitimacy, then it will try to counteract the outcome, and vice versa (Håkansson et al., 2009).

\section{External and internal triggers that change the opportunities for future interactions}

The second research question was: What triggers deliberate action by a start-up and its partner? The analysis demonstrates that an external trigger often marked the start of the relationship. This finding is similar to the results reported by Holmen et al. (2005) who found in a case study of a small Dutch company that its counterparties initiated the first contact, the contact was initiated by a direct counterparty or the contact was initiated at a public meeting, such as a trade show or trade fair. It may be that the start-up in this case did not directly initiate a relationship with a potential partner as it had only restricted attention from key decision makers in its partner's organisation. Although the importance of establishing the start-up's first relationships is widely recognized (La Rocca et al., 2013), research shows that start-ups often find it very difficult to contact the right individuals in a potential partner's organisation (Das \& He, 2006; Prashantham \& Birkinshaw, 2008). Furthermore, the analysis shows that internal events were equally likely to occur as external events during the relationships. This supports the findings of several authors (e.g. Ariño \& de la Torre, 1998; Medlin, 2004) who found that organisational action is the result of incidents that occur either inside or outside the interaction context.

More importantly, however, the findings reveal that action is triggered by events that expand as well as constrain the opportunities for future interaction. This is in conflict with the findings of Ariño and de la Torre (1998) who found that if the value from the relationship could increase then the initial agreements are executed, but no re-negotiations would follow which may lead to a set of revised agreements beyond the initial one. However, they did a longitudinal case study on the interaction between two partners in a failed joint venture, whereas in this case all the relationships continue to exist. Therefore, the difference may be explained by the fact that in successful relationships partners act on opportunities for further collaboration, while in failing partnerships they do not. Another explanation may be found in the focus of Ariño and de la Torre (1998) on events that triggered action when the relationship was already established, while this paper also included the initial interaction episodes in the analysis. The results show that in the early stages there are always opportunities to expand the collaboration. In contrast, in later stages partners have to resolve conflicts as a result of changes in the internal and external conditions of the relationship. Therefore, it may be that Ariño and de la Torre (1998) would have identified events expanding the opportunities for future collaboration that actually triggered action if they would have researched the partners' interaction from the start of the relationship. Taken together, these findings imply that the ultimate success or failure - as well as the stage of a relationship - is important to the nature of the triggers that occur. 


\section{Modes of interaction to consciously affect interaction}

The third research question was formulated as follows: What modes of interaction do a start-up and its partners use? The analysis demonstrates that the start-up and its partners used all six interaction modes. This confirms that the six proposed interaction modes, based on the work of Tjemkes and Furrer (2010) and Lui and Ngo (2005) on established organisations, can also be applied to start-ups. The results of this paper showed that the start-up and its partners used the interaction modes to a similar extend with the exception of acquiesce. This contradicts the findings of Ariño et al. (2008) who found that entrepreneurial firms are less likely to act, and thus avoid their partner, in the presence of governance misalignments than large firms. In this case, the start-up and its partners did not experience either excessive or insufficient governance that required action which may explain the contradictory findings. However, it confirms the results of Thorgren et al. (2012) who demonstrated that small firms are more likely to acquiesce than larger firms. It may be that the start-up was more likely to comply with the requests of its partners because it was asymmetrically dependent on that partner. For example, the start-up stated that it complied with all the advice of the teaching hospital regarding the European grant proposal as it did not have the required knowledge of how to write a good proposal. Research into established organisations has already demonstrated that certain characteristics of a relationship, such as dependence and trust, influence organisational interaction (e.g. Lui \& Ngo, 2005; Tjemkes \& Furrer, 2010). However, the underlying rationale for taking a particular action can be expected to differ between start-ups and established organisations because of their differences in their efforts to build legitimacy, the type and frequency of external demands, how much they dependent on the relationship and the goals of their organisation (Thorgren et al., 2012).

In addition, the analysis reveals that an important aspect of create is the involvement of third parties. This confirms the findings from Corsaro, Ramos, Henneberg, and Naudé (2011) who demonstrate that network characteristics affect organisational action in a relationship. At the same time, it suggests that the mode of interaction also affects the network in which the relationship is embedded. By involving the third partner into the relationship between the start-up and a particular partner, the balance between the relationships in its network changes. Thus, this confirms the notion of the IMP approach that neither a single organisation nor a single relationship acts in isolation; each relationship will be affected by and affects to a greater or lesser extent the relationships to which it is connected.

\section{Interaction: the action-reaction loops between counterparties}

The fourth research question was: How do the interaction modes of a start-up and its partners cooccur? The analysis shows that the interaction mode was either exactly the same or at least was of the same nature. Acquiesce, compromise and create co-occurred during the interaction episodes between the start-up and its partners while manipulate, avoid and defy happened together. Acquiescence, compromising and creation have in common that these interaction modes follow or consider the wishes of the partners. Avoidance, defying and manipulation share that a partner tries to force counterparty in a particular direction. This dichotomy overlaps with the two approaches to networking identified by the IMP approach: coerce and concede. Through coercion organisations try to direct specific aspects of interaction in accordance with their own intent, while by conceding they follow the wishes of their partner (Håkansson et al., 2009). Yet the analysis suggests that start-ups and their counterparties have multiple opportunities to choose from in the way they coerce or concede. Also, the analysis reveals a pattern in the development of the start-up's and its partners' interaction modes during the relationship from acquiescence and compromise, to manipulation, defiance and avoidance and eventually creation. This pattern may be caused by the development of the trigger over time; in the early stages there are opportunities to expand collaboration which leads to more conceding modes of interaction while in later stages conflicts arise that result in more coercing modes of interaction. However, as soon as the partners realise that they could harm the relationship by acting coercively, they try to develop a solution to the mutual problem. Indeed, the IMP literature argues that as the relationship between partners develops through interaction, they have to agree on more details of their relationship than in the beginning when 'everything' is still possible (Håkansson et al., 2009). This pattern in the evolution of the interaction modes over time emphasises that a focus on a single type of action, as described in the work of Thorgren et al. (2012) and Ariño et al. (2008), limits our understanding of how action evolves over time. 


\section{The outcome of interaction on the actors involved, their resources and activities}

The final research question can be expressed as: What is the outcome of the interaction process between a start-up and its partner? This case shows that interaction episodes had either converting, inhibiting or mixed outcomes. This confirms contemporary literature that outcomes can be either positive and negative (Edvardsson et al., 2008; Elo \& Törnroos, 2005). On the other hand, the mixed outcomes also imply that partners do not always perceive the outcome in the same way and that there may be both positive and negative aspects of the outcome. Previous research, such as that by Tjemkes and Furrer (2010), Lui and Ngo (2005) and Ariño et al. (2008), into organisational action in relationship has mainly focused on its antecedents; what triggers action by a partner and why does a partner chooses a particular action? Although it is important to be able to determine in what situation a particular interaction mode can be used, it does not say anything about whether that is the best action to use. Without considering the outcomes of an action, it is impossible to assess whether that particular mode of interaction will be beneficial or harmful to a specific relationship. It may be that previous studies did not research outcomes because the multidimensional character of relationship outcomes makes them hard to interpret (Ford et al., 2008; Håkansson et al., 2009). Conversely, previous research may have implicitly assumed the outcome of certain actions in advance. When acquiescing, compromising and creating, the partner takes the interests of the counterparty into account. Therefore, these modes of interaction are generally expected to result in a converting outcome. On the other hand, avoidance, defiance and manipulation challenge the interests of the other partner. Consequently, these modes of interaction are usually expected to cause an inhibiting outcome. Although the analysis of this case seems to confirm the latter assumption, a conceeding interaction mode did not always result in a converting outcome. In these instances, it appeared that the partners were unable to use the preferred mode of interaction due to internal restrictions or because the interaction process was negatively influenced by external factors. Therefore, the mode of interaction is influenced not only by willingness, but also by the ability to act in a particular way (Oliver, 1991).

Additionally, it can be concluded that there seems to be a close linkage between trigger, mode of interaction, interaction and outcome. If the trigger expands the opportunities for collaboration, the start-up and its partner acted in a conceding way (if they were able to) and this led to a converting outcome. However, if the trigger constrains opportunities for further interaction, the start-up and its partner acted in a coercive way or creative way, and this resulted in an inhibiting or converting outcome respectively. In summary, it is not necessarily the case that conceding and coercive actions lead to converting and inhibiting outcomes respectively.

\section{CONCLUSION}

This paper has contributed to the existing literature on start-ups' actions in relationships by researching how a start-up interacted with its partners, and offers process-focused explanations in this start-up's attempt to embed in a pre-existing network. This was done by developing a conceptual research model in which interaction and dynamics are key aspects. This model was used to analyse the interaction episodes of a start-up in the medical device business with its partners. The results show a high co-occurrence of interaction modes which emphasises the interactive nature of the start-up's actions. In addition, they reveal an evolution of interaction modes over the course of the relationship, a clear link between trigger, action, interaction and outcome, and an impact of previous episodes on current ones. All three findings highlight the dynamic nature of the start-up's actions. Moreover, it was found that: (a) triggers can be internal or external in origin and can expand or constrain the opportunities for future interaction; (b) the start-up used a variety of modes of interaction and (with the exception of acquiescence) to a similar extent to its partners; and (c) the start-up and its partners rely on their network to create novel and potentially useful solutions to conflicts. In conclusion, this paper shows that the start-up's actions were not one-sided and stable, but interactive and dynamic.

\section{IMPLICATIONS FOR FUTURE RESEARCH}

This paper provides six directions for future research. Firstly, previous literature and this paper provide contradictory results regarding the importance of opportunities for organisational action. As a result, future research may wish to further explore if and how 'beneficial' situations as opposed to 
'adverse' situations result in organisational action and in turn affect the outcomes of the relationship. Secondly, the co-occurrence of interaction modes in a single episode and the development pattern of interaction modes during the relationship, stress the importance of analysing the regularities and the recurrence of action in relationships. In other words, interaction modes should be studied in relationship to other actions both preceding and following it. Lui and Ngo (2005) identified three action patterns to characterise cooperative processes: action acquiescence, action simplicity and action reciprocity. As their research was based on established organisations, future research should address the question if these interaction patterns also apply to start-ups. The interaction patterns in single episodes and over multiple episodes that appeared in this research can be used as the starting point to further develop and study the interaction patterns of start-ups. Thirdly, the conclusions were drawn from 18 episodes of a single start-up which limits the ability to say something meaningful about the relationships between trigger, mode of interaction, interaction and outcome in other contexts, i.e. startups in other industries or with other types of relationships. Nevertheless, the results could form the basis for hypotheses on the relationship between these aspects that can be tested in a larger and more divers sample of start-ups. Fourthly, the discussion reveals that several factors, such as relationship characteristics and perceptions of the past and future interaction, influence the preference for a particular type of action in an episode. Taking into account these factors in future research will help scholars to explain why start-ups and their partners act in the ways in which they do. Fifthly, the research revealed that the start-up and its partner relied on their network to create innovative solutions to their problems. Therefore, it would be interesting to initiate further research on how an interaction mode of a partner in a relationship affects and is affected by the surrounding network. Finally, managers do not only need to know what modes of interaction can be used in a certain situation, but also what the action with the most beneficial outcome is. Therefore, future research into organisational actions in relationships should involve both the antecedents of actions and their outcomes to be of practical value.

\section{PRACTICAL IMPLICATIONS}

The findings of this paper also have several implications for the managers, owners and directors of start-ups. Firstly, and most importantly, managers of start-ups have the ability to act in a variety of ways over time and in a variety of relationships. Although they do not have complete control the outcome of the interaction process, they do influence it with their actions. The case shows that if the start-up acquiesced, compromised or created it was more likely to result in converting outcomes, whereas when it avoided, defied or manipulated it was more likely to result in inhibiting outcomes. Secondly, managers of start-ups do not only have to act in response to internal or external events that constrain the opportunities for future interaction, but also to opportunities that expand the scope for future collaboration. Thirdly, they have to closely consider the ways in which they are going to act or react because partners are likely to act in a similar way. If a manager wants a partner to concede it should not act coercively because that would probably trigger a coercive reaction. Fourthly, managers of start-ups have to be aware that they can and need to rely on their network to resolve conflicts with their partners. Fifthly, they need to create an understanding of their own and their partners' interaction patterns. In this way, they will be better able to anticipate the actions and reactions of their partners. Finally, they can stimulate the initiation of relationships by seeking media attention, attending both public and private meetings and using existing partners to connect to potentially new partners.

\section{AKNOWLEDGEMENT}

The authors would like to thank the in-depth criticisms and constructive comments of the reviewers at the IMP workshop in Manchester. In addition, they greatly appreciate the valuable remarks on a previous version of this paper. This research was funded through FP7 grant number 305654 from the European Commission to the PCDIAB consortium, www.pcdiab.eu. 


\section{REFERENCES}

Aaboen, L., Dubois, A., \& Lind, F. (2011). Start-ups starting up: Firms looking for a network. The IMP Journal, 5(1), 42-58.

Aaboen, L., Dubois, A., \& Lind, F. (2013). Strategizing as networking for new ventures. Industrial Marketing Management, 42(7), 1033-1041.

Ariño, A., \& de la Torre, J. (1998). Learning from Model Failure: Towards an Evolutionary Model of Collaborative Ventures. Organization Science, 9(3), 306-325.

Ariño, A., Ragozzino, R., \& Reuer, J. J. (2008). Alliance dynamics for entrepreneurial firms. Journal of Management Studies, 45(1), 147-168.

Bizzi, L., \& Langley, A. (2012). Studying processes in and around networks. Industrial Marketing Management, 41(2), 224-234.

Corsaro, D., Ramos, C., Henneberg, S. C., \& Naudé, P. (2011). Actor network pictures and networking activities in business networks: An experimental study. Industrial Marketing Management, 40(6), 919-932.

Das, T. K., \& He, I. Y. (2006). Entrepreneurial firms in search of established partners: Review and recommendations. International Journal of Entrepreneurial Behaviour and Research, 12(3), 114-143.

Das, T. K., \& Teng, B. S. (2002). The dynamics of alliance conditions in the alliance development process. Journal of Management Studies, 39(5), 725-746.

Doorewaard, H., \& Verschuren, P. (2010). Designing a research project (2nd ed.): The Hague: Boom Lemma Uitgevers.

Edvardsson, B., Holmlund, M., \& Strandvik, T. (2008). Initiation of business relationships in servicedominant settings. Industrial Marketing Management, 37(3), 339-350.

Eisenhardt, K. M. (1989). Building theories from case study research. The Academy of Management Review, 14(4), 532-532.

Elo, M., \& Törnroos, J. (2005). Relationships and networks-events enabling and inhibiting corporate internationalisation. Paper presented at the 21st IMP conference, Rotterdam.

Farrell, D. (1983). Exit, voice, loyalty, and neglect as responses to job dissatisfaction: A multidimensional scaling study. Academy of Management Journal, 26(4), 596-607.

Ford, D., Gadde, L., Håkansson, H., Snehota, I., \& Waluszewski, A. (2008). Analysing business interaction. Paper presented at the 24st IMP Conference Upssala.

Ford, D., \& Mouzas, S. (2008). Is there any hope? The idea of strategy in business networks. Australasian Marketing Journal, 16(1), 64-78.

Geyskens, I., \& Steenkamp, J. B. E. M. (2000). Economic and social satisfaction: Measurement and relevance to marketing channel relationships. Journal of Retailing, 76(1), 11-32.

Gibbert, M., Ruigrok, W., \& Wicki, B. (2008). Research notes and commentaries: what passes as a rigorous case study? Strategic Management Journal, 29, 1465-1474.

Håkansson, H., \& Ford, D. (2002). How should companies interact in business networks? Journal of Business Research, 55(2), 133-139.

Håkansson, H., Ford, D., Gadde, L., Snehota, I., \& Waluszewski, A. (2009). Business in networks. Chichester: John Wiley \& Sons.

Håkansson, H., Olsen, P. I., \& Bakken, T. (2013). Agency and economizing in interacted economies. The IMP Journal, 7, 106-111.

Håkansson, H., \& Waluszewski, A. (2007). Knowledge and innovation in business and industry: The importance of using others. London: Routledge.

Håkansson, H., \& Waluszewski, A. (2013). A never ending story-Interaction patterns and economic development. Industrial Marketing Management, 42(3), 443-454.

Halinen, A. , Medlin, C. J., \& Törnroos, J. (2012). Time and process in business network research. Industrial Marketing Management, 41(2), 215-223.

Harrison, D., Holmen, E., \& Pedersen, A. (2010). How companies strategise deliberately in networks using strategic initiatives. Industrial Marketing Management, 39(6), 947-955.

Hirschman, A. O. (1970). Exit, Voice and Loyalty: responses to decline in firms, organizations and states. Cambridge, MA: Harvard University Press. 
Holmen, E., Roos, K., Kallevag, M., Raesfeld, A. von, Boer, L. de, \& Pedersen, A. (2005). How do relationships begin? Paper presented at the 21st IMP Conference, Rotterdam.

La Rocca, A., Ford, D., \& Snehota, I. (2013). Initial relationship development in new business ventures. Industrial Marketing Management, 42(7), 1025-1032.

Langley, A. (1999). Strategies for theorizing from process data. Academy of Management Review, 24(4), 691-710.

Langley, A., Smallman, C., Tsoukas, H., \& Van de Ven, A. H. (2013). Process studies of change in organization and management: unveiling temporality, activity, and flow. Academy of Management Journal, 56(1), 1-13.

Leonard-Barton, D. (1990). A dual methodology for case studies: Synergistic use of a longitudinal single site with replicated multiple sites. Organization Science, 1(3), 248-266.

Lui, S. S, \& Ngo, H.. (2005). An Action Pattern Model of Inter-firm Cooperation*. Journal of Management Studies, 42(6), 1123-1153.

Medlin, C. J. (2004). Interaction in business relationships: A time perspective. Industrial Marketing Management, 33(3), 185-193.

Oliver, C. (1991). Strategic responses to institutional processes. Academy of Management Review, 16(1), 145-179.

Parkhe, A. (1998). Understanding trust in international alliances. Journal of world business, 33(3), 219-240.

Ping, R. A. (1993). The effects of satisfaction and structural constraints on retailer exiting, voice, loyalty, opportunism, and neglect. Journal of Retailing, 69(3), 320-352.

Ping, R. A. (1999). Unexplored antecedents of exiting in a marketing channel. Journal of Retailing, 75(2), 218-241.

Prashantham, S., \& Birkinshaw, J. (2008). Dancing with Gorillas: How small companies can partner effectively with MNCS. California Management Review, 51(1), 6-23+23.

Pressey, A. D., \& Qiu, X. X. (2007). Buyer-supplier relationship dissolution: The Chinese context. Journal of Business and Industrial Marketing, 22(2), 107-117.

Raesfeld, A. von, \& Roos, K. (2008). How should a small company interact in its business network to sustain its exchange effectiveness? Creativity and innovation management, 17(4), 271-280.

Ring, Peter S., \& Van de Ven, A. H. (1994). Developmental processes of cooperative interorganizational relationships. The Academy of Management Review, 19(1), 90-118.

Snehota, I. (2011). New business formation in business networks. The IMP Journal, 5(1), 1-9.

Thorgren, S., Wincent, J., \& Boter, H. (2012). Small firms in multipartner R\&D alliances: Gaining benefits by acquiescing. Journal of Engineering and Technology Management, 29(4), 453467.

Tjemkes, B., \& Furrer, O. (2010). The antecedents of response strategies in strategic alliances. Management Decision, 48(7), 1103-1133.

Van de Ven, A. H. (1992). Suggestion for studying strategy process: A research note. Strategic Management Journal, 13(Summer), 169-191. 